\title{
Incentives towards Economic Integration as the Second-Best Tariff Policy *
}

\author{
Kazuharu Kiyono ${ }^{\dagger}$
}

August, 2006

\begin{abstract}
Economic integratin such as free trade areas (FTA) and customs uions (CU) allows importing countries to circumvent the constraint of non-discriminatory tariffis posed by the most favorened nation clause in GATT and to employ (incomplete) tariff discrimination. Thus the second-best choice for the importing country, if it does regional integration, is to choose as the partner the exporting country which would have been subject to the lower tariff under the full tariff discrimination. Regardless of the mode of competition, we will find that such a partner tends to be less efficient than other exporting countries, which implies that voluntary regional integration leads the world economy to less efficient resource allocations.
\end{abstract}

Keywords: economic integration, tariff discrimination, second-best policy, conjectural variations, oligopoly

JEL classification: F12, F13, F15

\section{Introduction}

Since the seminal article by Viner (1950), there has been a vast literature on theories of economic integration. Somewhat problematic concepts of "trade creation" and "trade diversion" have been reexamined in various frameworks when discussing the welfare effects of integration. Although Meade elucidated those concepts within a framework of a small country and the partial equilibrium approach, there are many other studies casting doubts on those conceptual tools such as Bhagwati and Panagriya (1996). Even without agreement on how to use the two concepts, the economists have also extended the theory of economic integration to imperfect competition as well as economic growth. ${ }^{1}$

However there is another question for research, often less focused in this literature. That is, what country is chosen as the FTA partner? From the viewpoint of the exporting country,

\footnotetext{
*Very preliminary. Please do not quote without the author's permission.

${ }^{\dagger}$ Faculty of Political Science \& Economics, Waseda University. E-mail address: kazr@waseda.jp

${ }^{1}$ See the extensive surveys by Panagariya (2000) and Baldwin and Venables (1995).
} 
it would welcome any economic integration leading to the preferential removal of the currently imposed import tariffs. However from the viewpoint of the importing country, it is vital which exporting country's tariff to remove, for the change in its terms of trade greatly depends on its choice of economic integration partners. ${ }^{2}$

For the large importing country, the best trade policy is tariff discrimination or importprice discrimination by making the best of its monopsony power in trade. As is implied by the application of the price discrimination to monopsony, when the marginal import costs differ among the exporting countries, the importing country can maximize its welfare by equating those marginal import costs and thus minimizing the total import costs. Put differently, from the viewpoint of the standard optimal tariff theory shows, the international monopsonist should set the lower import price or equivalently the higher import tariff to the exporting country with the smaller price elasticity of supply, But such tariff discrimination is disallowed in GATT under the most favored nation clause. The only ways to circumvent this constraint are formations of free trade areas (FTA's) and customs unions (CU's). Since such economic integration allows the importing country to employ incomplete but discriminatory tariffs, we may pose the problem of choosing the partner for economic integration as the one of removing the tariffs on either the exporting country subject to the higher or lower tariff under the full tariff discrimination.

Since lowering the higher optimal discriminatory tariff to zero tends to cause the greater costs to the importing country, the intuition tells us that the importing country has the greater incentive to choose the exporting country with the lower optimal discriminatory tariff as its partner. In this paper, we deal with FTA formation and discuss how this intuition holds not only in perfect competition but also in more general imperfect competition. ${ }^{3}$ As we will see later, the marginal import cost tends to be lower for the exporting country with the less efficient technologies, which makes the optimal discriminatory tariff lower. This implies that the importing country tends to choose the less efficient technology as its FTA partner.

In section 2, we review the puzzle of welfare-worsening FTA formations with an exporting country having the lower marginal cost posed by Bhagwati and Panagriya (1996) and elucidate the problem of tariff discrimination governing the welfare effect of FTA formation. In section 3, we construct the basic model of FTA formation as the second-best discriminatory policy in perfect competition, and establishe the basic principle for the importing country's choosing the FTA partner. In section 4, we extend the model to imperfect competition described by the

\footnotetext{
${ }^{2}$ For example, McMillan and MacCann (1981) explores this problem from the viewpoint of complementarity and substitution of goods traded in perfect competition. But there are little research explicitly dealing with the FTA partner choice in imperfect competition except Kiyono (1993) and Raff (2001), though Raff (2001) discusses the problem from the viewpoint of tariff revenue maximization.

${ }^{3}$ The approach is essentially the same as Kiyono (1993) discussing the importing country's choice on the FTA partner within a homogenous Cournot oligopoly market. But the present paper makes clear how the second-best approach covers not only perfect competition but also imperfect competition and generalizes the discussion in two directions. First, the paper covers the case of non-constant marginal costs. And Second, it deal with the quasi-Cournot oligopoly market in which the firms hold non-Cournot conjectural variations.
} 
conjectural variations equilibria, and demonstrate that the results in perfect competition still hold. Lastly in section 5, we extend the analysis by incorporating the domestic production in the importing country. We will find its effect on the tariff discrimination and the choice of the FTA partners with some more remarks on future possible directions for the research.

\section{FTA Formation for a Large Importing Country}

Let us make a brief review over the examples of Bhagwati and Panagriya (1996), illustrated by Figures 1 and 2, which show the complicated welfare effects of FTA formation by a large country importing from two exporting countries in perfect competition.

\subsection{Ambiguous Welfare Effects of FTA Formation?}

In each of the two figures, the downward sloping curve $D D^{\prime}$ represents the import demand curve of the importing country while the horizontal line $c_{L} c_{L}^{\prime}$ indicates the export supply curve of country $L$ and the upward sloping line $c_{H} c_{H}^{\prime}$ that of country $H$. Initially the importing country imposes the nondiscriminatory or uniform specific import tariff $t^{U}$ on the imports from both exporting countries. Thus the total supply curve facing the private sector in the importing country is given by the kinked curve $c_{L}^{T} U c_{H}^{T \prime}$, leading to the equilibrium shown by point $E$. Of the total import $c_{H}^{T} E, c_{H}^{T} U$ comes from country $L$ and $U E$ from country $H$. The trade surplus for the private sector in the importing country is given by the triangle $D c_{H}^{T} E$, and the tariff revenue by the square $c_{H}^{T} c_{H} U^{\prime} U$, the sum of which constitutes the total welfare of the importing country.

Then what if the importing country forms a FTA with country $L$ given the external tariff $t^{U} ?$

In Figure 1, the market supply curve facing the importing country's private sector is now given by the kinked curve $c_{L} L c_{H}^{T \prime}$, so that the market equilibrium in the importing country is still given by point $E$. Since the import from country $L$ is free, the tariff revenue earned before the FTA formation, measured by $\square c_{H}^{T} c_{H} U^{\prime} U$ now vanishes, and furthermore substitution of the import $c_{H}^{T} E$ from country $H$ to country $L$ also makes the country lose the extra tariff revenue measured by $\square U U^{\prime} L^{\prime} L$. Therefore the importing country becomes worse off suffering from the total loss $\square c_{H}^{T} c_{H} L^{\prime} L$. Since the loss of the tariff revenue is due to the trade diversion effect, the importing country's welfare loss entirely comes from this welfare-worsening trade diversion effect.

The situation is a little more complicated in Figure 2. The market supply curve facing the private sector in the importing country is now given by the kinked curve $c_{L} F c_{H}^{T \prime}$, so that the new equilibrium is given by point $L$. All the imports come from country $L$ with the lower domestic price $p_{L}$ and more consumption $p_{L} L$. The importing country gains from more consumption as much as $\square c_{H}^{T} p_{L} F E$ (the trade creation effect), while it loses all the tariff 


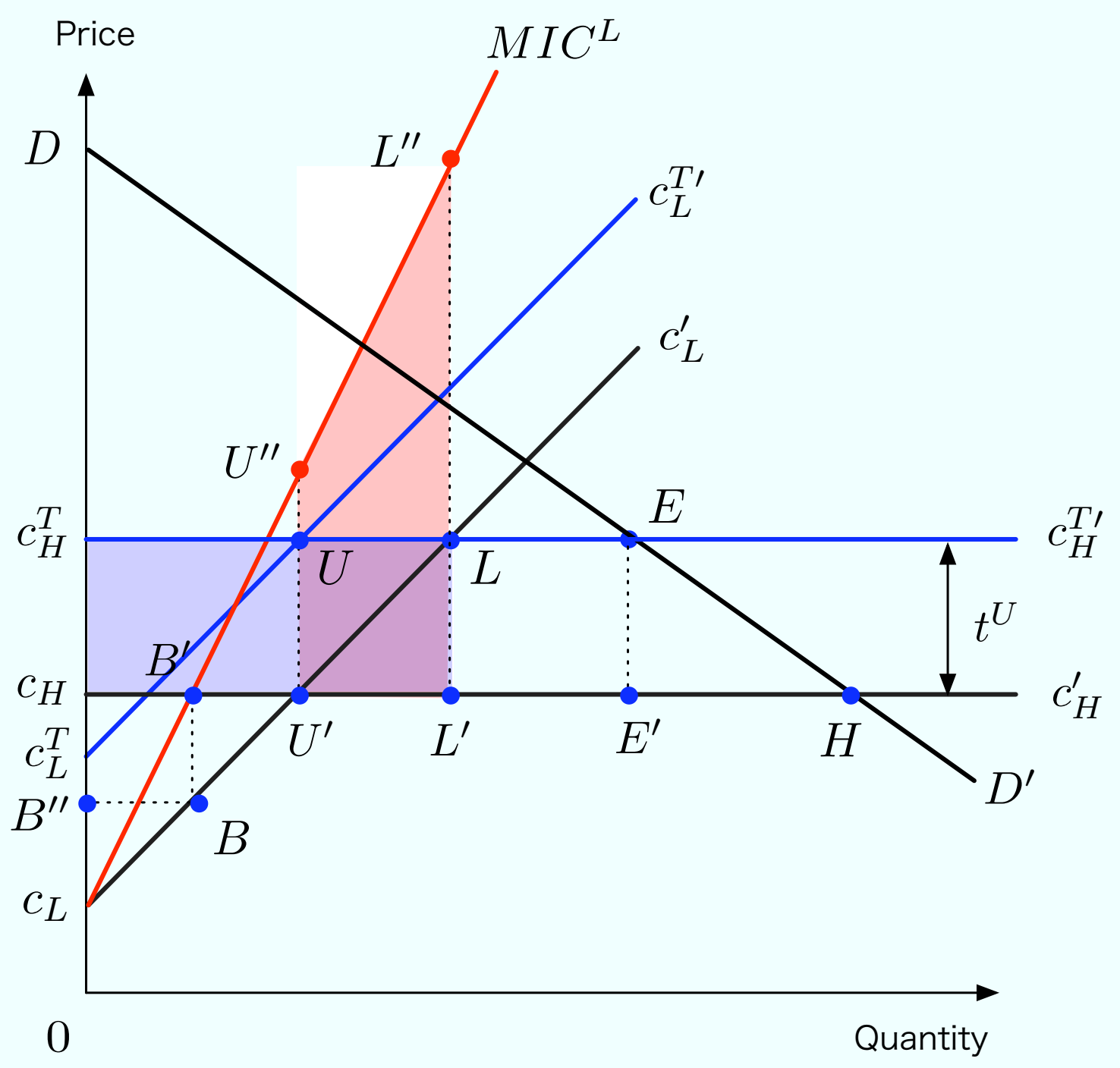

Figure 1: Bhagwati-Panagariya Example 1 
revenue earned before FTA formation, i.e., $c_{H}^{T} c_{H} E^{\prime} E$ (the trade diversion effect). Thus its net welfare gain is given by $\triangle E A L$ minus $\square p_{L} c_{H} E^{\prime} A$, or equivalently the gains from trade creation minus the costs from trade diversion. The welfare effect of FTA formation now depends on which effect of trade creation and diversion dominates the other.

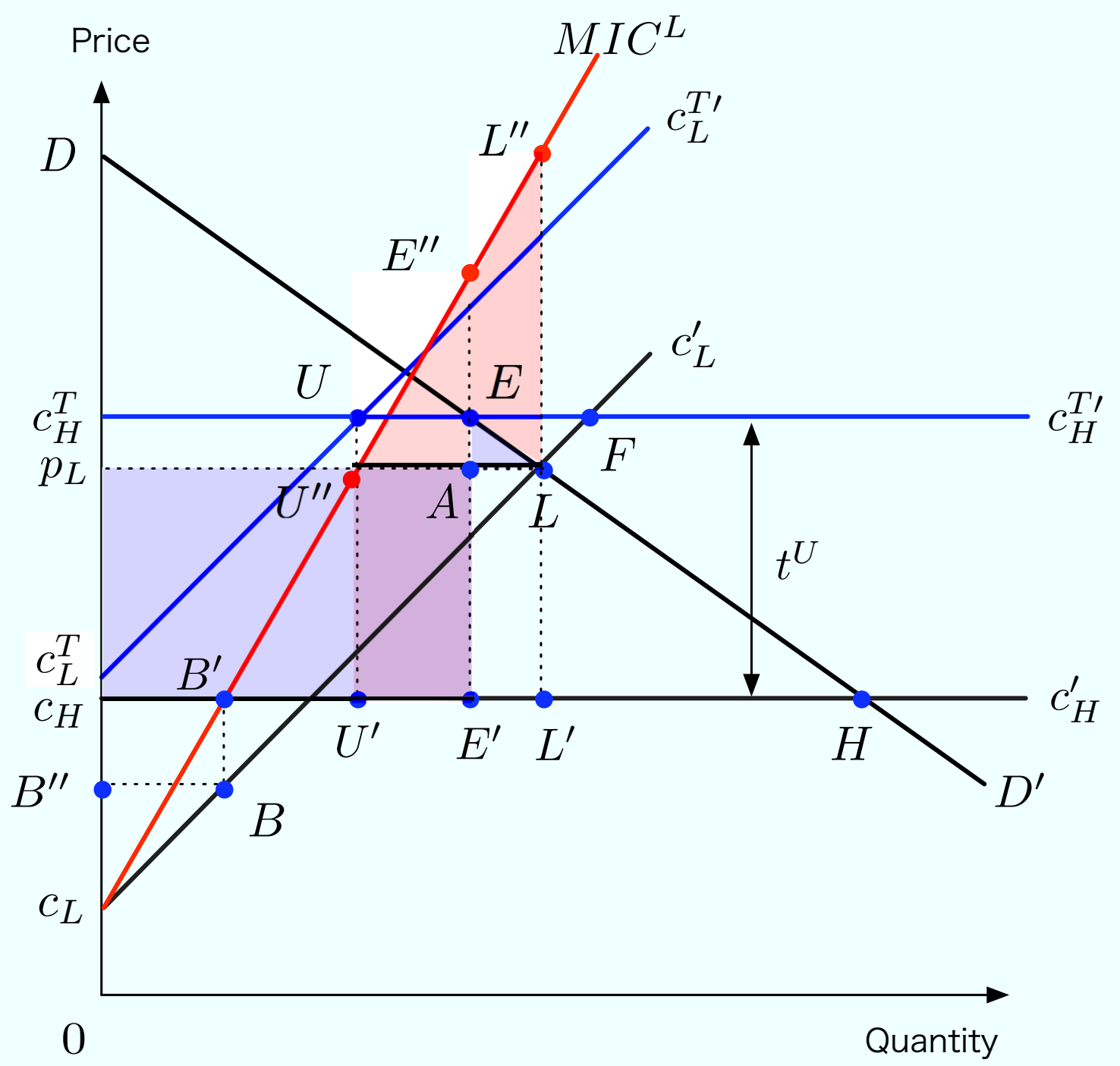

Figure 2: Bhagwati-Panagariya Example 2

\subsection{Tariff Discrimination as Import-Price Discrimination}

This familiar discussion overlooks the important status of the importing country in the world market, i.e., the monopsonist. Sine it faces upward-sloping export supply curves, the importing country can make the best of its monopsony power.

And as the monopsonist, the best strategy for the importing country is price discrimination 
over the exporters. It first minimizes the total import costs by equating the marginal import costs from each country and then decides on the amount of the total import by equating the own marginal benefit of consumption with the equalized marginal import costs between the two exporting countries.

In each of Figures 1 and 2, the marginal import cost from country $L$, given by curve $M I C^{L}$, is located above the upward-sloping export supply curve $c_{L} c_{L}^{\prime}$, while that of country $H$ coincides its horizontal export supply curve $c_{H} c_{H}^{\prime}$. Thus the marginal import cost curve for the price-discriminating importing country is given by the kinked curve $c_{L} B^{\prime} c_{H}^{\prime}$. It is the best for the importing country to import as much as $c_{H} H$, of which $c_{H} B^{\prime}$ comes from country $L$ and $B^{\prime} H$ from country $H$. To achieve this first-best state, the importing country should impose the discriminatory tariffs to the two exporting countries, $B B^{\prime}$ on country $L$ and zero tariff on country $H$. Import-price discrimination involves tariff discrimination. The total welfare is then given by the trade surplus of the private sector measured by $\Delta D c_{H} H$ and the tariff revenue $\square c_{H} B^{\prime \prime} B B^{\prime}$. That is, FTA formation with country $H$, rather than with country $L$, should be chosen by the importing country.

\subsection{Choice of FTA Partners}

However, when the country is subject to the most favored nation clause, it cannot undertake full tariff discrimination. It can enforce only an imperfect one trough economic integration such as FTA and CU by providing preferential zero tariffs to the partner countries. The available alternative policies for the importing country is either uniform tariffs to all the exporting countries or imperfect tariff discrimination through economic integration. Let us take FTA as an example of economic integration throughout the rest of the paper.

The intuition tells us that it is better for the importing country to form a FTA with the exporting country whose optimal discriminatory tariff is lower than the other, for the costs of required tariff reduction should be smaller than the FTA with the other exporting country.

In fact, as the two Figures show, the marginal import cost of country $L$, whose optimal discriminatory tariff is the higher, is greater than that of country $H$, so that the import substitution from country $H$ to country $L$ after FTA formation with country $L$ increases the total import costs and thus makes the importing county worse off. For example, in Figure 1, although the total import volume is kept unchanged, the import substitution raises the total import costs as much as the trapezoid shape of $U^{\prime \prime} U^{\prime} L^{\prime} L^{\prime \prime}$, which is another expression for the country's welfare loss from FTA formation with country $L$. And in Figure 2, the importing country suffers from two types of welfare loss. The first is the increased import costs from import substitution, measured by $\square U^{\prime \prime} U^{\prime} E^{\prime} E^{\prime \prime}$, and the second is the excessive consumption due to the marginal import cost greater than the marginal benefit of consumption, measured by the trapezoid shape of $E^{\prime \prime} E F L^{\prime \prime}$. Thus, the importing country is strictly worse off by FTA formation with country $L$, though this result has not been recognized in the previous 
literature.

\section{FTA Formation in Perfect Competition}

Let us generalize the analysis in the previous section, and elucidate further the properties of the candidates as FTA partners.

\subsection{Competitive Model}

As in the previous section, consider a country totally depending on the imports from two exporting countries, $H$ and $L$, for consumption of a certain good. There are $n_{i}$ identical competitive firms in each exporting country $i \in\{H, L\}$ with the total export cost function $C_{i}\left(x_{i}\right)$ where $x_{i}$ denotes the individual output for export in country $i$. Let $X_{i}:=n_{i} x_{i}$ denote the total export of country $i, X_{T}:=\sum_{k} X_{k}$ the total exports, and $p$ the domestic price in the importing country. Then the profit of an individual firm in country $i$ is given by

$$
\pi^{i}:=p x_{i}-C_{i}\left(x_{i}\right)-t_{i} x_{i}
$$

where $t_{i}$ denotes the specific tariff imposed by the importing country's government on exporting country $i$. We assume

Assumption 1 The marginal cost of each firm in each country is non-decreasing in the output, i.e., $C_{i}^{\prime \prime}\left(x_{i}\right)>0$ for $i=H, L$.

Since each exporting firm maximizes its profit by equating the marginal cost with the gross-tariff export price, denoted by $v_{i}=p-t_{i}$. The condition defines the individual firm's export supply price function given by

$$
v_{i}=v^{i}\left(x_{i}\right):=C_{i}^{\prime}\left(x_{i}\right)
$$

Its inverse is the individual export supply function $s^{i}\left(v_{i}\right)$, and the total export supply by country $i$ expressed by $S^{i}\left(X_{i}: n_{i}\right):=n_{i} s^{i}\left(v_{i}\right)$.

There are two remarks in order here. First, the price elasticity of country $i$ 's export supply is the same as that of the individual export supply, which we denote by $\varepsilon_{i}^{S}\left(v_{i}\right)$. Second, since this price elasticity is equal to the inverse of the output elasticity of marginal cost, there holds

$$
\varepsilon_{i}^{S}\left(v_{i}\right)=\frac{1}{\sigma_{i}\left(s^{i}\left(v_{i}\right)\right)}
$$

where $\sigma_{i}\left(x_{i}\right):=d \ln C_{i}^{\prime}\left(s^{i}\left(v_{i}\right)\right) / d \ln x_{i}$ denotes the output elasticity of country $i$ 's marginal cost or equivalently the output elasticity of the export supply price, $d \ln v^{i}\left(x_{i}\right) / d \ln x_{i}$. The two countries differ with respect to the price elasticity of export or the output elasticity of the marginal cost as follows. 
Assumption 2 There holds $\varepsilon_{H}^{S}(v)>\varepsilon_{L}^{S}(v)$ for all common export price $v$. Or equivalently, there holds $\sigma_{H}\left(x_{H}\right)<\sigma_{L}\left(x_{L}\right)$ for all $\left(x_{H}, x_{L}\right)$ satisfying $C_{H}^{\prime}\left(x_{H}\right)=C_{L}^{\prime}\left(x_{L}\right)$.

The total import costs, denoted by $T I C$, is then given by

$$
\operatorname{TIC}\left(X_{H}, X_{L} ; n_{H}, n_{L}\right):=\sum_{k} v^{k}\left(\frac{X_{k}}{n_{k}}\right) X_{k} .
$$

The marginal import cost from country $i$, denoted by $M I C^{i}$, is given by

$$
M I C^{i}\left(X_{i}\right):=\frac{\partial T I C\left(X_{H}, X_{L}\right)}{\partial X_{i}}=v^{i}\left(\frac{X_{i}}{n_{i}}\right)+x_{i} C_{i}^{\prime \prime}\left(x_{i}\right)=C_{i}^{\prime}\left(x_{i}\right)\left(1+\sigma_{i}\left(x_{i}\right)\right),
$$

which is independent of the import from the other exporting country. ${ }^{4}$

The welfare of the importing country is expressed by

$$
W=u\left(\sum_{k} X_{k}\right)-P\left(\sum_{k} X_{k}\right) \cdot \sum_{k} X_{k}+\sum_{k} t_{k} X_{k},
$$

which can be rewritten

$$
W(\boldsymbol{X})=u\left(\sum_{k} X_{k}\right)-\operatorname{TIC}\left(X_{H}, X_{L}\right),
$$

where $\boldsymbol{X}:=\left(X_{H}, X_{L}\right)$ and use was made of (1). Without loss of generality, we assume that $W(\boldsymbol{X})$ is strictly concave.

\subsection{Optimal Tariff Discrimination}

Let us first explore the policy of optimal tariff discrimination as import-price discrimination. Let us express the equilibrium values with superscript $D$. Then the optimal import from each country should satisfy the following conditions for welfare maximization. ${ }^{5}$

Condition 1: Minimization of the total import costs given the total import volume, i.e., $M I C^{H}\left(X_{H}^{D}\right)=M I C^{L}\left(X_{L}^{D}\right)$.

Condition 2: Equality between the marginal consumption benefit and the equalized marginal import costs, i.e., $P\left(X_{T}^{D}\right)=M I C^{H}\left(X_{H}^{D}\right)$.

\footnotetext{
${ }^{4}$ As we will see later, this independence property fails to hold in imperfect competition.

${ }^{5}$ We assume here, though not stated explicitly in the text,

$$
M I C^{i}\left(X_{i}^{m}\right)>M I C^{j}(0) \quad(i, j=H, L ; j \neq i),
$$

where $X_{i}^{m}:=\max _{\left\{X_{i}\right\}}\left\{W(\boldsymbol{X}) \mid X_{j}=0\right\}$. If this condition fails, then the first-best tariff rate is given by $t_{i}^{m}:=P\left(X_{i}^{m}\right)-v^{i}\left(X_{i}^{m}\right)$, which automatically prevents the import from country $j$. Then FTA formation is definitely worse than this optimal uniform tariff policy.
} 
Since $M I C^{i}\left(X_{i}\right)=C_{i}^{\prime}\left(x_{i}\right)+x_{i} C_{i}^{\prime \prime}\left(x_{i}\right)$ and the specific tariff rate is equal to the difference between the domestic price (=the marginal consumption benefit) and the export price, Condition 2 above implies that the optimal discriminatory tariff on country $i$, denoted by $t_{i}^{D}$, is given by

$$
t_{i}^{D}=C_{i}^{\prime}\left(x_{i}^{D}\right) \sigma_{i}\left(x_{i}^{D}\right)
$$

This is the specific-tariff version of the familiar optimal tariff formula. The examples of Bhagwati and Panagriya (1996) are based on the marginal cost function given by

$$
C_{i}^{\prime}\left(x_{i}\right)=c_{i}+\frac{x_{i}}{s_{i}}
$$

where $c_{i}$ and $s_{i}$ are positive constants. The marginal import cost from each country is then equal to $M I C^{i}\left(X_{i}\right)=c_{i}+2 \frac{x_{i}}{s_{i}}$, so that Condition 2 implies

$$
x_{i}^{D} C_{i}^{\prime \prime}\left(x_{i}^{D}\right)=\frac{x_{i}^{D}}{s_{i}}=\frac{1}{2}\left(p^{D}-c_{i}\right)
$$

where $p^{D}:=P\left(X_{T}^{D}\right)$. Thus, the optimal discriminatory tariff is equal to

$$
t_{i}^{D}=\frac{1}{2}\left(p^{D}-c_{i}\right)(i=H, L)
$$

by virtue of (6). Therefore for the marginal cost functions (BP-MC) discussed by Bhagwati and Panagriya (1996), the difference in the optimal discriminatory tariffs depends only on each country's choke price for export, $c_{i}$, and thus country $L$ faces the higher tariff under the optimal tariff discrimination.

Proposition 1 When both exporting countries are subject to the marginal costs given by (BP-MC) under perfect competition, the exporting country with the lower choke price face the higher optimal discriminatory import tariff.

\subsection{Optimal Uniform Tariff Policy}

Now consider the optimal uniform tariff policy, i.e., the non-discriminatory import-pricing to both exporting countries. As both exporting countries face the same tariff and thus the same export price, their marginal costs should be equal, i.e., $C_{H}^{\prime}\left(\frac{X_{H}}{n_{H}}\right)=C_{L}^{\prime}\left(\frac{X_{L}}{n_{L}}\right)$. This equality governs the export by country $L$ as a function of the export by country $H$ for any rate of uniform tariffs, which we express by $X_{L}=\gamma_{H}\left(X_{H}\right)$. This function satisfies

$$
\gamma_{H}^{\prime}\left(X_{H}\right)=\frac{n_{L} C_{L}^{\prime \prime}\left(x_{L}\right)}{n_{H} C_{H}^{\prime \prime}\left(x_{H}\right)}=\frac{X_{L} \sigma_{H}\left(x_{H}\right)}{X_{H} \sigma_{L}\left(x_{L}\right)}>0
$$


Using this function $\gamma_{H}\left(X_{H}\right)$, we may express the optimal uniform-tariff policy problem faced by the importing country as $\max _{\left\{X_{H}\right\}} W\left(X_{H}, \gamma_{H}\left(X_{H}\right)\right)$ where we assume that $W\left(X_{H}, \gamma_{H}\left(X_{H}\right)\right)$ is strictly concave in $X_{H}$. For characterizing this equilibrium, the following lemma is of a great use.

Lemma 1 For any uniform tariff, there holds $\frac{\partial W\left(X_{H}, X_{L}\right)}{\partial X_{H}}>\frac{\partial W\left(X_{H}, W_{L}\right)}{\partial X_{L}}$, or equivalently $M I C^{H}\left(X_{H}\right)<M I C^{L}\left(X_{L}\right)$.

This follows straightforward from the following inequality based on the definition of the marginal import costs.

$$
\begin{aligned}
& \frac{\partial W(\boldsymbol{X})}{\partial X_{H}}-\frac{\partial W(\boldsymbol{X})}{\partial X_{L}} \\
= & \left\{p-C_{H}^{\prime}\left(x_{H}\right)\left(1+\sigma_{H}\left(x_{H}\right)\right)\right\}-\left\{p-C_{L}^{\prime}\left(1+\sigma_{L}\left(x_{L}\right)\right)\right\} \\
= & C_{H}^{\prime}\left(x_{H}\right)\left\{\sigma_{L}\left(x_{L}\right)-\sigma_{H}\left(x_{H}\right)\right\}>0 \\
& \quad\left(\because C_{H}^{\prime}\left(x_{H}\right)=C_{L}^{\prime}\left(x_{L}\right)\right. \text { under the uniform tariffs, and Assumption 2) }
\end{aligned}
$$

Now we characterize the optimal uniform tariff policy equilibrium as the solution to $\max _{\left\{X_{H}\right\}} W\left(X_{H}, \gamma_{H}\left(X_{H}\right)\right)$. Let us represent the variables associated with the resulting optimal uniform tariff policy equilibrium with superscript " $U *$ ". Then the associated first-order condition for welfare maximization is given by

$$
\begin{aligned}
0 & =\frac{\partial W\left(X_{H}^{U *}, \gamma_{H}\left(X_{H}^{U *}\right)\right)}{\partial X_{H}}+\frac{\partial W\left(X_{H}^{U *}, \gamma_{H}\left(X_{H}^{U *}\right)\right)}{\partial X_{L}} \gamma_{H}^{\prime}\left(X_{H}^{U *}\right) \\
& =\left\{P\left(X_{T}^{U *}\right)-M I C^{H}\left(X_{H}^{U *}\right)\right\}+\left\{P\left(X_{T}^{U *}\right)-M I C^{L}\left(X_{L}^{U *}\right)\right\} \gamma_{H}^{\prime}\left(X_{H}^{U *}\right) \\
& <\left(1+\gamma_{H}^{\prime}\left(X_{H}^{U *}\right)\right) \frac{\partial W\left(X_{H}^{U *}, \gamma_{H}\left(X_{H}^{U *}\right)\right)}{\partial X_{H}}\left(\because \gamma_{H}^{\prime}\left(X_{H}\right)>0 \text { and Lemma } 1\right),
\end{aligned}
$$

which implies $\frac{\partial W\left(X_{H}^{U *}, \gamma_{H}\left(X_{H}^{U *}\right)\right)}{\partial X_{H}}>0$, and thus $\frac{\partial W\left(X_{H}^{U *}, \gamma_{H}\left(X_{H}^{U *}\right)\right)}{\partial X_{L}}<0$ due to $\gamma_{H}^{\prime}\left(X_{H}\right)>0$. Therefore we have established

Lemma 2 At the optimal uniform tariff policy equilibrium, there holds $\frac{\partial W\left(X_{H}^{U *}, \gamma_{H}\left(X_{H}^{U *}\right)\right)}{\partial X_{H}}>$ $0>\frac{\partial W\left(X_{H}^{U *}, \gamma_{H}\left(X_{H}^{U *}\right)\right)}{\partial X_{L}}$.

\subsection{FTA Formation}

What if the importing country abandons the optimal uniform tariff policy and forms a FTA with either exporting country? Let us denote by $X_{k}^{i}(i, k \in\{H, L\})$ the import from country $k$, by $W^{i}$ the importing country's welfare when a FTA is formed with country $i$, and by $W^{U *}$ the welfare under the optimal uniform tariff policy. Since the welfare function is strictly 
concave, there holds the following inequality governing the welfare between the two states.

$$
\begin{aligned}
& W^{i}-W^{U *} \\
\leq & \frac{\partial W\left(X_{H}^{U *}, \gamma_{H}\left(X_{H}^{U *}\right)\right)}{\partial X_{H}}\left(X_{H}^{i}-X_{H}^{U *}\right)+\frac{\partial W\left(X_{H}^{U *}, \gamma_{H}\left(X_{H}^{U *}\right)\right)}{\partial X_{L}}\left(X_{L}^{i}-X_{L}^{U *}\right) .
\end{aligned}
$$

Then it is straightforward to derive the following proposition by virtue of the above inequality and Lemma 2.

Proposition 2 When the FTA formation with country $i$ gives rise to either (i) $X_{H}^{i} \leq$ $X_{H}^{U *}, X_{L}^{i} \geq X_{L}^{U *}$, or/and (ii) $X_{T}^{i} \leq X_{T}^{U *}$, then the importing country cannot get better off by the FTA formation.

This proposition indicates two sets of conditions for welfare-worsening FTA formation compared with the optimal uniform tariff policy. Condition (i) is immediate from (8) by virtue of Lemma 2. It implies that in sofar as the FTA expands the import from the partner but reduces the import from the non-partner, then the importing country gets worse off by the FTA formation with country $L$.

Condition (ii) can be obtained by rewriting (8) as follows.

$$
W^{i}-W^{*} \leq \frac{\partial W\left(X_{H}^{U *}, \gamma_{H}\left(X_{H}^{U *}\right)\right)}{\partial X_{H}}\left\{\left(X_{H}^{i}-X_{H}^{U *}\right)+\left(X_{L}^{i}-X_{L}^{U *}\right)\right\}
$$

where use was again made of Lemma 2. The condition implies that when the total import volume does not exceed after the FTA formation, then the importing country gets worse off than under the optimal uniform tariff policy.

In view of Proposition 2, when the importing country finds FTA formation better than the optimal uniform tariff policy, then the partner should be country $H$ facing the higher optimal discriminatory tariff and the FTA should expand the total import volume.

\section{FTA Formation in Imperfect Competition}

Let us extend our analysis towards imperfect competition à la Cournot. ${ }^{6}$ For simplicity of exposition, we additionally assume

Assumption 3 The inverse demand function $P\left(X_{T}\right)$ is concave, i.e., $P^{\prime \prime}\left(X_{T}\right) \leq 0$.

This assumption ensures the individual output to be always a strategic substitute to the others' and the equilibrium, whenever it exists, to be unique and globally stable. ${ }^{7}$

\footnotetext{
${ }^{6}$ The model framework is essentially the same as Brander and Spencer (1984).

${ }^{7}$ This assures the so-called "Hahn condition" for stability of Cournot equilibrium (Hahn (1962)). See also the modern approach to the problem of uniqueness and stability of Cournot equilibrium discussed by Kolstad and Mathiesen (1987), Okuguchi (1976) and Gaudet and Salant (1991) for instance. Their discussion can be readily applied to the present conjectural variations approach.
} 
On the other hand, we relax Assumption 1 as follows so that we can take account of the case of constant marginal costs,too.

Assumption 4 The marginal cost of each firm in each country is non-decreasing in the output, i.e., $C_{i}^{\prime \prime}\left(x_{i}\right) \geq 0$ for $i=H, L$.

We also discuss more general mode of competition than the standard Cournot model, by employing the conjectural variations approach. ${ }^{8}$

Assumption 5 Each firm in country $i(\in\{H, L\})$ has the same constant value of conjectural variations $\lambda_{i}(>0)$, which represents how much it expects the total output to increase along with its output expansion.

Then the first-order condition for profit maximization is

$$
0=P\left(X_{T}\right)+\lambda_{i} x_{i} P^{\prime}\left(X_{T}\right)-C_{i}^{\prime}\left(x_{i}\right)-t_{i},
$$

which implies that the equilibrium individual outputs are the same for all the firms located in the same country. Thus, the equilibrium condition for the industry as a whole in country $i$ is expressed by

$$
0=P\left(X_{T}\right)+\frac{\lambda_{i}}{n_{i}} X_{i} P^{\prime}\left(X_{T}\right)-C_{i}^{\prime}\left(\frac{X_{i}}{n_{i}}\right)-t_{i}
$$

As in perfect competition, $v_{i}:=P\left(X_{T}\right)-t_{i}$ represents the import price from country $i$ (or the export price facing country $i$ ). (9) then defines the export supply price function of each exporting country as

$$
v^{i}\left(X_{i}, X_{T} ; n_{i}, \lambda_{i}\right):=C_{i}^{\prime}\left(\frac{X_{i}}{n_{i}}\right)+I M R^{i}\left(X_{i}, X_{T} \frac{\lambda_{i}}{n_{i}}\right),
$$

where

$$
I M R^{i}\left(X_{i}, X_{T} ; \frac{\lambda_{i}}{n_{i}}\right):=-\frac{\lambda_{i}}{n_{i}} X_{i} P^{\prime}\left(X_{T}\right)
$$

represents the individual monopoly rent earned per unit of output by the individual firm in country $i$ and satisfies

$$
\begin{aligned}
& \frac{\partial I M R^{i}\left(X_{i}, X_{T}\right)}{\partial X_{i}}=-\frac{\lambda_{i}}{n_{i}} P^{\prime}\left(X_{T}\right)=\frac{1}{X_{i}}\left\{P\left(X_{T}\right)-C_{i}^{\prime}\left(x_{i}\right)-t_{i}\right\}>0, \\
& \frac{\partial I M R^{i}\left(X_{i}, X_{T}\right)}{\partial X_{T}}=-P^{\prime \prime}\left(X_{T}\right) \frac{\lambda_{i}}{n_{i}} X_{i} \geq 0,
\end{aligned}
$$

\footnotetext{
${ }^{8}$ Compared with the previous studies such as Gatsios (1990), Hwan and Mai (1991), Kiyono (1993), Raff (2001) and Saggi (2004), conjectural variations allow us to explore various modes of competiton covering perfect equilibria, Cournot-Nash equilibria, and compelte or incomplete joint profit maximization. See Kamien and Schwartz (1983) and Cabral (1995) for the usefulness of this concept.
} 
by virtue of Assumption 3. As expressed by (10), the export price of each country now depends not only on its own output but also on the other's, and exceeds the marginal cost by the individual monopoly rent. In view of (12) and (13), one should also note that the individual monopoly rent of each firm is increasing in both its own output and the industry output.

Let $\boldsymbol{X}:=\left(X_{H}, X_{L}\right)$ represent the import vector. Then the total import cost function, denoted by $\operatorname{TIC}(\boldsymbol{X} ; \boldsymbol{n}, \boldsymbol{\lambda}):=\sum_{k} v^{k}\left(X_{k}, X_{T}\right) X_{k}$, is also expressed as follows.

$$
\begin{aligned}
T I C(\boldsymbol{X} ; \boldsymbol{n}, \boldsymbol{\lambda}) & =\sum_{k} X_{k} \cdot C_{k}^{\prime}\left(\frac{X_{k}}{n_{k}}\right)+\sum_{k} X_{k} \cdot I M R^{k}\left(X_{k}, X_{T}\right) \\
& =\sum_{k} X_{k} \cdot C_{k}^{\prime}\left(\frac{X_{k}}{n_{k}}\right)-P^{\prime}\left(\sum_{k} X_{k}\right) \sum_{k} \frac{\lambda_{k}}{n_{k}} X_{k}^{2} .
\end{aligned}
$$

The marginal import cost from country $i$, denoted by $M I C^{i}\left(X_{i}, X_{j}\right)$, is now given by ${ }^{9}$

$$
\begin{aligned}
M I C^{i}\left(X_{i}, X_{j}\right) & :=v^{i}\left(X_{i}, X_{T}\right)+x_{i} C_{i}^{\prime \prime}\left(x_{i}\right) \\
& +X_{i} \frac{\partial I M R^{i}\left(X_{i}, X_{T}\right)}{\partial X_{i}}+\sum_{k} X_{k} \frac{\partial I M R^{k}\left(X_{k}, X_{T}\right)}{\partial X_{T}},
\end{aligned}
$$

where the second term is just the same as in perfect competition as expressed by (4) while the third and fourth terms are specific to imperfect competition and both are positive by virtue of (12) and (13). They represent the increased monopoly rents due to country $i$ 's output increase. In the following analysis, the following alternative expression for the marginal import costs is of a great use.

$$
M I C^{i}\left(X_{i}, X_{j}\right)=x_{i} C_{i}^{\prime \prime}\left(x_{i}\right)-C_{i}^{\prime}\left(x_{i}\right)-2 t_{i}+2 P\left(X_{T}\right)-P^{\prime \prime}\left(X_{T}\right) \sum_{k} \frac{\lambda_{k}}{n_{k}} X_{k}^{2},
$$

where use was made of (9) and (15).

As in perfect competition, the welfare of the importing country, denoted by $W(\boldsymbol{X} ; \boldsymbol{n}, \boldsymbol{\lambda})$, is then given by

$$
W(\boldsymbol{X} ; \boldsymbol{n}, \boldsymbol{\lambda}):=U\left(\sum_{k} X_{k}\right)-T I C(\boldsymbol{X} ; \boldsymbol{n}, \boldsymbol{\lambda}),
$$

\footnotetext{
${ }^{9}$ More specifically, as with country $H$ for instance, its marginal import cost function is defined as

$$
M I C^{H}\left(X_{H}, X_{L}\right):=\frac{d T I C\left(X_{H}, X_{H}+X_{L}\right)}{d X_{H}}=\frac{\partial T I C\left(X_{H}, X_{H}+X_{L}\right)}{\partial X_{H}}+\frac{\partial T I C\left(X_{H}, X_{H}+X_{L}\right)}{\partial X_{T}} .
$$
}


which is essentially the same as (5) in perfect competition. As in perfect competition, we assume the following for making the succeeding analysis meaningful. 10

Assumption 6 The welfare function $W(\boldsymbol{X} ; \boldsymbol{n}, \boldsymbol{\lambda})$ is strictly concave in $\boldsymbol{X}$.

This completes the description of the model. As has already been discussed, the critical difference in the welfare expression between perfect and imperfect competition is that the import cost from each exporting country, $v_{i} X_{i}$, depends on the amount of export by the other exporting country in imperfect competition. ${ }^{11}$

Hereafter we extend the previous analysis in perfect competition to imperfect competition. First, we explore the properties of the optimal tariff discrimination,

\subsection{Optimal Tariff Discrimination in Imperfect Competition}

As in perfect competition, the import vector $\boldsymbol{X}^{D}:=\left(X_{H}^{D}, X_{L}^{D}\right)$ associated with the optimal tariff discrimination equilibrium, should satisfy ${ }^{12}$

Condition 1': Minimization of the total import costs given the total import volume,

$$
\text { i.e., } M I C^{H}\left(X_{H}^{D}, X_{L}^{D}\right)=M I C^{L}\left(X_{L}^{D}, X_{H}^{D}\right) \text {, }
$$

Condition 2': Equality between the marginal consumption benefit and the equalized marginal import costs, i.e., $P\left(X_{T}^{D}\right)=M I C^{H}\left(X_{H}^{D}, X_{L}^{D}\right)$.

Let us make clear first by using Condition $1^{\prime}$ what governs the difference in the optimal discriminatory tariffs on the exporting countries as in the case of perfect competition. This Condition $1^{\prime}$, coupled with (MIC-ALT), yields

$$
x_{H}^{D} C_{H}^{\prime \prime}\left(x_{H}^{D}\right)-C_{H}^{\prime}\left(x_{H}^{D}\right)-2 t_{H}^{D}=x_{L}^{D} C_{L}^{\prime \prime}\left(x_{L}^{D}\right)-C_{L}^{\prime}\left(x_{L}^{D}\right)-2 t_{L}^{D}
$$

which gives rise to

$$
t_{L}^{D}-t_{H}^{D}=\frac{1}{2}\left\{C_{H}^{\prime}\left(x_{H}^{D}\right)\left(1-\sigma_{H}\left(x_{H}^{D}\right)\right)-C_{L}^{\prime}\left(x_{L}^{D}\right)\left(1-\sigma_{L}\left(x_{L}^{D}\right)\right)\right\} .
$$

\footnotetext{
${ }^{10}$ The previous studies formulate the importing country's welfare as a function of the tariff vector and assume that it is concave in the tariff vector. However, the condition to ensure this conavity is more complicated than when we use the welfare as a function of the import vector as formulated below. In fact, given concavity of the gross consumption benefit function $U\left(X_{T}\right)$, concavity of the inverse demand function $P\left(X_{T}\right)$, and increasing marginal costs of each firm's export, the welfare function given by (16) is concave in the import vector when there hold $C^{\prime \prime \prime}(x) \geq 0$ for $i=H, L$, and $P^{\prime \prime \prime}\left(X_{T}\right) \leq 0$.

${ }^{11}$ In perfect competition, country $i$ 's export supply function is solely determined by its own exports, i.e., $\partial v^{i}\left(X_{i}, X_{j}\right) / \partial X_{j}=0$. This in fact holds when $\lambda_{i}=0$.

${ }^{12}$ We also assume essentially the same condition as in perfect competition mentioned in footnote 5 . That is,

$$
M I C^{i}\left(X_{i}^{m}, 0\right)>M I C^{j}\left(0, X_{i}^{m}\right) \quad(i, j \in\{H, L\} ; j \neq i),
$$

where $X_{i}^{m}:=\arg \max _{\left\{X_{i}\right\}}\left\{W(\boldsymbol{X}) \mid X_{j}=0\right\}$.
} 
When the marginal cost functions are given by (BP-MC), then the above tariff difference is reduced to

$$
t_{L}^{D}-t_{H}^{D}=\frac{1}{2}\left(c_{H}-c_{L}\right)
$$

Surprisingly enough, the difference in the optimal discriminatory tariffs is just the same as in perfect competition. ${ }^{13}$

Proposition 3 When the marginal costs are expressed by $(B P-M C)$, i.e., $C_{i}^{\prime}\left(x_{i}\right)=c_{i}+\frac{x_{i}}{s_{i}}$, then there holds $t_{L}^{D}-t_{H}^{D}=\frac{1}{2}\left(c_{H}-c_{L}\right)$, and the exporting country with the lower choke price $c_{i}$ is subject to the higher discriminatory tariff.

By Condition $2^{\prime}$ coupled with (MIC), we can obtain the general formula for optimal discriminatory specific tariffs which holds both in perfect and imperfect competition as follows.

$$
t_{i}^{D}=x_{i}^{D} C_{i}^{\prime \prime}\left(x_{i}^{D}\right)+X_{i}^{D} \frac{\partial I M R^{i}\left(X_{i}^{D}, X_{T}^{D}\right)}{\partial X_{i}}+\sum_{k} X_{k} \frac{\partial I M R^{k}\left(X_{k}^{D}, X_{T}^{D}\right)}{\partial X_{T}},
$$

where use was made $t_{i}=P\left(X_{T}\right)-v^{i}\left(X_{i}, X_{T}\right)$.

The first term on the right hand side is the effect of increasing marginal costs working both in perfect and imperfect competition. Since $x_{i} C_{i}^{\prime \prime}\left(x_{i}\right)=C_{i}^{\prime}\left(x_{i}\right) \sigma_{i}\left(x_{i}\right)$ and $\sigma_{i}\left(x_{i}\right)$ corresponds to the inverse of the price elasticity of export supply, we may call it the elasticity effect.

On the other hand, as we have discussed on the marginal import costs, the second and third terms are specific to imperfect competition and both are positive. The second term shows the effect of increased individual monopoly rents, and the third term the effect of increased industry monopoly rents. Unlike the standard literature on taxing oligopoly firms in trade, the above formula indicates that the optimal tariff does extract not the foreign monopoly rents but the increased monopoly rents.

Proposition 4 When the importing country enforces the optimal discriminatory tariff policy, then the associated specific tariff on exporting country $i$, denoted by $t_{i}^{D}$, should satisfy

$$
t_{i}^{D}=x_{i}^{D} C_{i}^{\prime \prime}\left(x_{i}^{D}\right)+X_{i}^{D} \frac{\partial I M R^{i}\left(X_{i}^{D}, X_{T}^{D}\right)}{\partial X_{i}}+\sum_{k} X_{k} \frac{\partial I M R^{k}\left(X_{k}^{D}, X_{T}^{D}\right)}{\partial X_{T}},(i=H, L) .
$$

Note that the formula above holds even when we allow the country importing from more than two exporting countries.

\footnotetext{
${ }^{13}$ Gatsios (1990) and Hwan and Mai (1991) derives the following result for the imporing country importing from two countries, each of which has a single exporting firm, whereas Kiyono (1993) discusses for the case in which there are more than two symmetric firms in each exporting country, and Saggi (2004) proves it for the importing country importing from more than two countries. All these studies assume Cournot competition, i.e., $\lambda_{i}=1$ for all the firms in questin.
} 


\subsection{Optimal Uniform Tariffs and FTA Formation}

We may apply the same logic as in perfect competition and obtain the condition for welfareworsening FTA formation compared with the optimal uniform tariff policy. But there are new problems specific to imperfect competition.

First, Lemma 1, which played an important role to characterize the optimal uniform tariff policy in perfect competition, does not generally hold in imperfect competition. ${ }^{14}$

Second, the raise in the uniform tariff rate, having reduced the individual output in perfect competition, does not generally decrease all the firms' outputs in imperfect competition, though it decreases the total output. Since there is at least one country whose export is decreasing in the uniform tariff rate, we can apply the same approach as in perfect competition and obtain the following inequality, essentially the same as (8).

$$
W^{i}-W^{U *} \leq \frac{\partial W\left(\boldsymbol{X}^{U *}\right)}{\partial X_{H}}\left(X_{H}^{i}-X_{H}^{U *}\right)+\frac{\partial W\left(\boldsymbol{X}^{U *}\right)}{\partial X_{L}}\left(X_{L}^{i}-X_{L}^{U *}\right) .
$$

Thus there holds the following result with more reservations than in Proposition 2.

Proposition 5 The importing country gets worse off under the FTA formation with country $i$ than under the optimal uniform tariff policy if either of the following conditions holds at the optimal uniform tariff policy equilibrium.

$$
\begin{aligned}
& \text { (i) } \frac{\partial W\left(\boldsymbol{X}^{U *}\right)}{\partial X_{H}}>\max \left\{0, \frac{\partial W\left(\boldsymbol{X}^{U *}\right)}{\partial X_{L}}\right\} \text { and } X_{T}^{i} \leq X_{T}^{U *} \text {. } \\
& \text { (ii) } \frac{\partial W\left(\boldsymbol{X}^{U *}\right)}{\partial X_{H}}>0 \geq \frac{\partial W\left(\boldsymbol{X}^{U *}\right)}{\partial X_{L}} \text { and } X_{H}^{i} \leq X_{H}^{U *}, X_{L}^{i} \geq X_{L}^{U *} .
\end{aligned}
$$

\subsection{FTA Partner Switch and Changes in Welfare}

As has been made clear, we are unable to extend the analysis in perfect competition to imperfectly competitive markets. For this reason, we have to devise different approaches for finding the better FTA partner for the importing country. Fortunately, when we confine ourselves to the marginal costs given by (BP-MC), i.e., $C_{i}^{\prime}\left(x_{i}\right)=c_{i}+\frac{x_{i}}{s_{i}}$, then we can obtain several conditions for the better FTA candidate. This is because the equilibrium given any tariff policies satisfies the following useful property under (BP-MC).

Lemma 3 Assume that the marginal cost function in each exporting country is given by $(B P-M C)$. Then given the conjectural variations and the numbers of active firms in the exporting countries, the equilibrium total output is kept constant if $\sum_{k} n_{k} \cdot \frac{t_{k}}{\frac{1}{s_{k}}-\lambda_{k} P^{\prime}\left(X_{T}\right)}$ must be unchanged for the total output to be kept unchanged.

\footnotetext{
${ }^{14}$ However it does when the marginal costs are given by (BP-MC), for there holds

$$
M I C^{H}\left(X_{H}, X_{L}\right)-M I C^{L}\left(X_{L}, X_{H}\right)=c_{L}-c_{H}<0,
$$

by virtue of $c_{H}>c_{L}$. This also implies $\frac{\partial W(\boldsymbol{X})}{\partial X_{H}}>\frac{\partial W(\boldsymbol{X})}{\partial X_{L}}$. These results constitute the counterpart of Lemma 2 in imperfect competition.
} 
This can be proven as follows. First, when the marginal costs are given by (BP-MC), the first-order condition for profit maximization by each exporting firm, (9), is rewritten as

$$
P\left(X_{T}\right)+\frac{\lambda_{i}}{n_{i}} X_{i} P^{\prime}\left(X_{T}\right)-\left(c_{i}+\frac{X_{i}}{s_{i} n_{i}}+t_{i}\right)=0
$$

which gives rise to the following quasi-reaction function of exporting country $i$.

$$
X_{i}=R^{i}\left(X_{T}, t_{i}\right)=n_{i} \cdot \frac{P\left(X_{T}\right)-\left(c_{i}+t_{i}\right)}{\frac{1}{s_{i}}-\lambda_{i} P^{\prime}\left(X_{T}\right)} .
$$

The market equilibrium requires

$$
X_{T}=\sum_{k} n_{k} \cdot \frac{P\left(X_{T}\right)-c_{k}}{\frac{1}{s_{k}}-\lambda_{k} P^{\prime}\left(X_{T}\right)}-\sum_{k} n_{k} \cdot \frac{t_{k}}{\frac{1}{s_{k}}-\lambda_{k} P^{\prime}\left(X_{T}\right)},
$$

which establishes Lemma 3 above.

Using this Lemma 3, we directly compare the welfare between the FTA formation with country $H$ and the one with country $L$, where one should remember that the optimal discriminatory tariff is higher for country $L$ than for country $H$. We do this job by following two steps.

- Step 1: Given the total amount of imports at FTA with country $L$, switch the FTA partner from $L$ to $H$.

- Step 2: Adjust optimally the total imports and the external tariff to the non-partner $L$.

For making the analysis sensible enough, we focus our attention on the case in which the initial FTA with country $L$ imposes a strictly external tariff, $t_{H}^{L}>0$.

In Step 1, following Lemma 3, we confine ourselves to a certain total output $X_{T}^{L}$ and the tariff vector $\boldsymbol{t}=\left(t_{H}, t_{L}\right)$ satisfying

$$
\sum_{k} n_{k} \cdot \frac{t_{k}}{\frac{1}{s_{k}}-\lambda_{k} P^{\prime}\left(X_{T}\right)}=n_{H} \cdot \frac{t_{H}^{L}}{\frac{1}{s_{H}}-\lambda_{H} P^{\prime}\left(X_{T}^{L}\right)} .
$$

Then insofar the total output is unchanged at $X_{T}^{L}$, our marginal import cost from each each country can be replaced with what we may call the constrained marginal import cost, which shows the marginal import cost from each exporting country when the total import volume is kept constant.

As is shown by (10), given the marginal cost (BP-MC), the export price of each exporting country, given by

$$
v^{i}\left(X_{i}, X_{T}\right)=C_{i}^{\prime}\left(\frac{X_{i}}{n_{i}}\right)-\frac{\lambda_{i}}{n_{i}} X_{i} P^{\prime}\left(X_{T}\right)=c_{i}+\left(\frac{1}{s_{i} n_{i}}-\frac{\lambda_{i}}{n_{i}} P^{\prime}\left(X_{T}\right)\right) X_{i},
$$


depends only on its export and it is linear in the own export when the total import volume $X_{T}$ is constant. and thus we may define its associated constrained marginal import cost, denoted by $\overline{M I C}^{i}\left(X_{i}, X_{T}\right)$, by

$$
\begin{aligned}
\overline{M I C}^{i}\left(X_{i}, X_{T}\right) & :=C_{i}^{\prime}\left(\frac{X_{i}}{n_{i}}\right)+\frac{X_{i}}{n_{i}} C_{i}^{\prime \prime}\left(\frac{X_{i}}{n_{i}}\right)-2 \frac{\lambda_{i}}{n_{i}} X_{i} P^{\prime}\left(X_{T}\right) \\
& =c_{i}+2\left(\frac{1}{s_{i} n_{i}}-P^{\prime}\left(X_{T}\right) \frac{\lambda_{i}}{n_{i}}\right) X_{i} .
\end{aligned}
$$

Note that in general this constrained marginal import cost has the following relation to the unconstrained one given by (MIC).

$$
M I C^{i}\left(X_{i}, X_{j}\right)=\overline{M I C}^{i}\left(X_{i}, X_{j}\right)-P^{\prime \prime}\left(X_{T}\right) \sum_{k} \frac{\lambda_{k}}{n_{k}} X_{k}^{2}
$$

so that (MIC-ALT) implies

$$
\overline{M I C}^{i}\left(X_{i}, X_{T}\right)=-c_{i}-2 t_{i}+2 P\left(X_{T}\right)
$$

Each country's constrained marginal cost curve is thus linear and strictly upward sloping as illustrated by Figures 3 and 4 . In each, the line segment $0_{H} 0_{L}$ is equal to the total import given by $X_{T}^{L}$ associated with the domestic price $p_{D}$ in the importing country. The import from country $H$ is measured rightward from point $0_{H}$, while the import from country $L$ is measured leftward from point $0_{L}$. The upward sloping curve $c_{i} v_{i}(i=H, L)$ shows the export price of exporting country $i$ and the upward sloping curve $c_{i} \overline{M I C}_{i}(i=H, L)$ its associated constrained marginal import cost curve.

The equilibrium of FTA with country $L$ is shown by point $F_{L}$, where the domestic price line $p_{D} p_{D}$ crosses the export price curve of country $L$. Of the total import, $L 0_{L}$ comes from country $L$, and $0_{H} L$ from country $H$. The tariff imposed on country $H, t_{H}^{L}$, is measured by the difference between its export price (measured by $L v_{H}^{L}$ ) and the domestic price, i.e., the line segment $v_{H}^{L} F_{L}$.

Now take the case illustrated by Figure 3 first and consider the switch of the FTA partner to country $H$ given the total amount of imports. This requires the export price of country $H$ to be equal to the domestic price, which is shown by point $F_{H}$. More import of $0_{H} H$ comes from country $H$, and the import from country $L$ decreases to $0_{L} H$ facing the tariff of $F_{H} v_{L}^{H}$.

The change in the total import costs are measured by the areas $\Delta M_{L}^{L} M_{H}^{L} D^{*}$ (showing the decreased costs) and $\Delta M_{L}^{H} M_{H}^{H} D^{*}$ (showing the increased costs), where point $D^{*}$ shows the equalized marginal import costs from the two exporting countries. When the importing country expands its import from country $H$ up to $0_{H} H$, the increased imports $L D^{* \prime}$ increases the import costs from country $H$ as much as the trapezoid shape of $M_{H}^{L} L D^{* \prime} D^{*}$ but decreases as much as the trapezoid shape of $M_{L}^{L} L D^{* \prime}$, which gives rise to net decrease in the total costs 


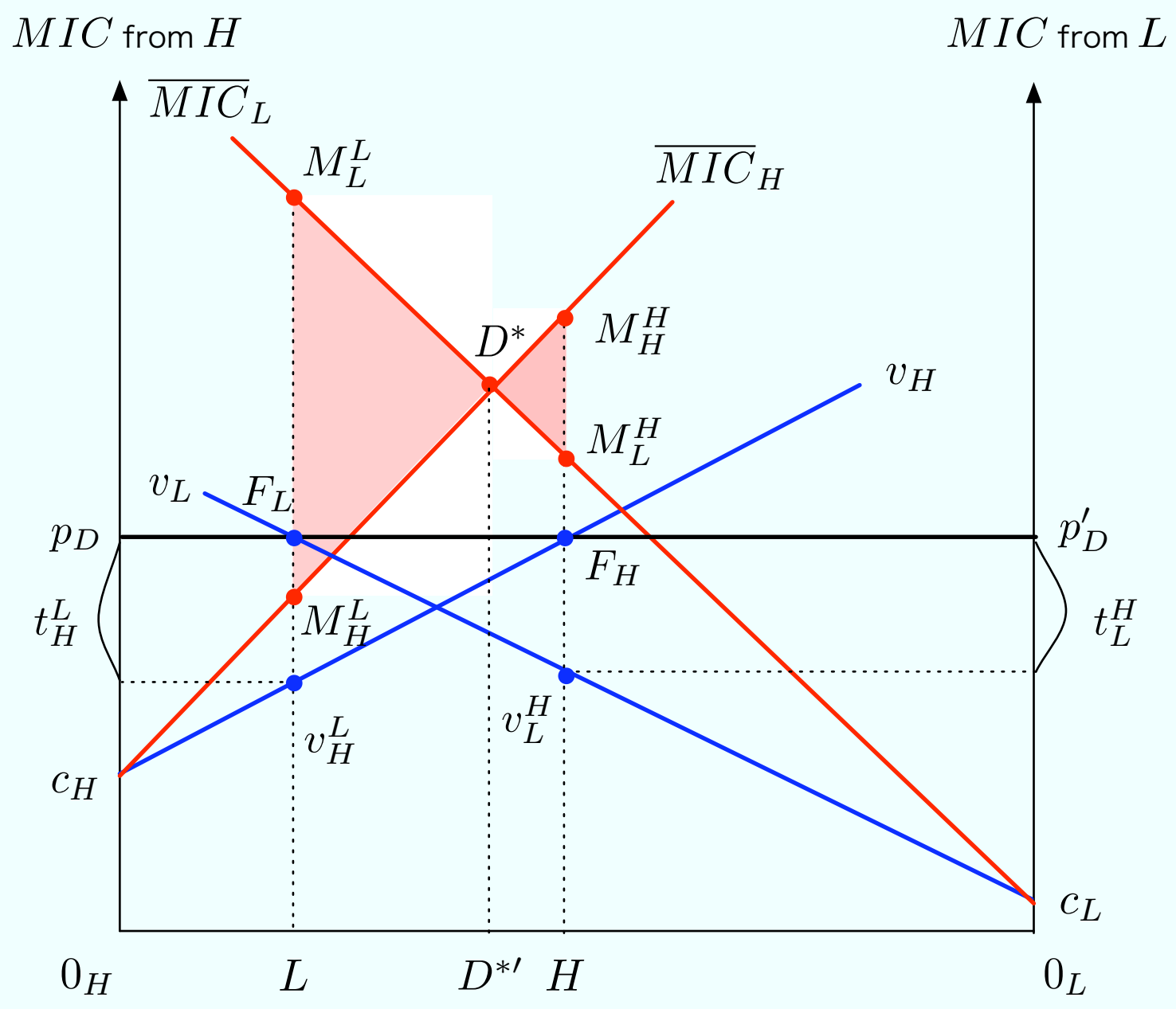

Figure 3: FTA Partner Switch - Case 1 
as much as $\Delta M_{L}^{L} M_{H}^{L} D^{*}$. But the further import from country $H$ raises the import cost from country $H$ as much as $D^{*} D^{* \prime} H M_{H}^{H}$ but reduces the import cost from country $L$ as much as $D^{*} D^{* \prime} M_{L}^{H}$, which amounts to net increase in the total import costs by $\Delta M_{L}^{H} M_{H}^{H} D^{*}$. Therefore the importing country gains from the FTA partner switch as much as $\Delta M_{L}^{L} M_{H}^{L} D^{*}$ minus $\Delta M_{L}^{H} M_{H}^{H} D^{*}$. As one can verify in view of the figure, the importing country is actually better off if and only if the following condition holds.

a Welfare-improving condition: The sum of country $H$ 's marginal import cost minus country $L$ 's at two FTA equilibria is strictly positive, i.e,

$$
\left(\overline{M I C}^{L}\left(X_{L}^{L}, X_{T}^{L}\right)-\overline{M I C}^{H}\left(X_{H}^{L}, X_{T}^{L}\right)\right)+\left(\overline{M I C}^{L}\left(X_{L}^{H}, X_{T}^{L}\right)-\overline{M I C}^{H}\left(X_{H}^{H}, X_{T}^{L}\right)\right)>0 .
$$

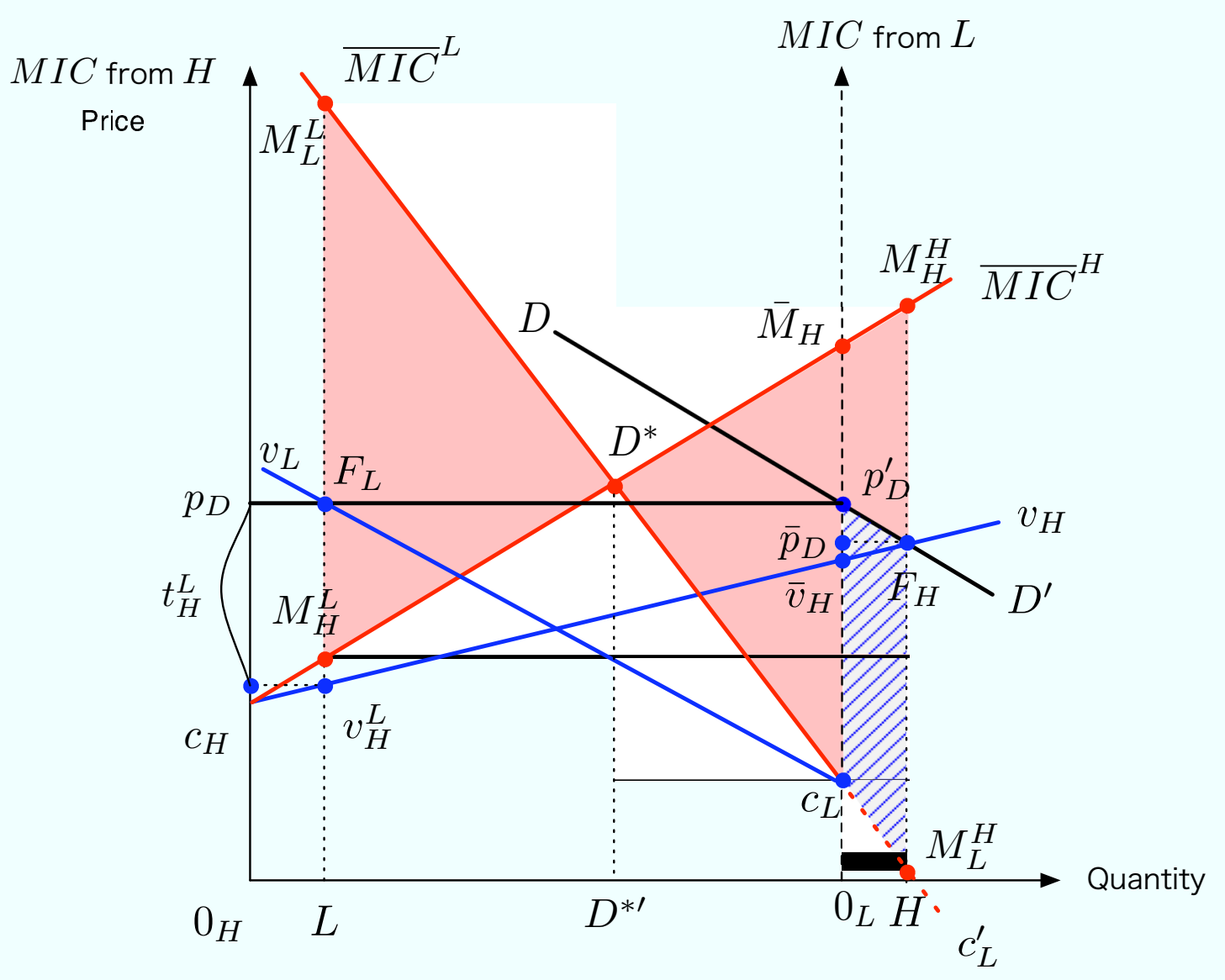

Figure 4: FTA Partner Switch - Case 2

Unlike Figure 3, Figure 4 indicates the case in which the export price of country $H$ supplying the total import, measured by $\bar{v}_{H}$, is lower than the domestic price $p_{D}$, so that the FTA formation with country $H$ requires the total import to increase. When the market demand curve of the importing country is given by the downward-sloping curve $D D^{\prime}$, then 
the FTA formation requires the market equilibrium to settle at point $F_{H}$ and to totally exclude the import from country $L$. The associated increase in the import costs is now measured by $\Delta D^{*} \bar{M}_{H} c_{L}$ plus the trapezoid area $\square \bar{M}_{H} p_{D}^{\prime} F_{H} M_{H}^{H}$. Note that when we extend the constrained marginal import cost curve of country $L$ up to what is shown by the curve $\overline{M I C}^{L} c_{L}^{\prime}$ and thus literally follow the above welfare-improving, then the increased import cost amounts to the area $\Delta D^{*} M_{L}^{H} M_{H}^{H}$, which is larger than what is actually incurred. Thus if the condition is satisfied, then the switch of the FTA partner is definitely welfare-improving for the importing country. For this reason, we hereafter employ the above condition for evaluating whether the switch of the FTA partner improves the importing country's welfare.

Let us give a more precise expression for this welfare-improving condition. By virtue of (20), the difference in the marginal import costs is equal to

$$
\overline{M I C}^{L}\left(X_{L}, X_{T}\right)-\overline{M I C}^{H}\left(X_{H}, X_{T}\right)=c_{H}-c_{L}+2\left(t_{H}-t_{L}\right),
$$

so that there hold

$$
\overline{M I C}^{L}\left(X_{L}, X_{T}\right)-\overline{M I C}^{H}\left(X_{H}, X_{T}\right)= \begin{cases}c_{H}-c_{L}+2 t_{H}^{L} & \text { under the FTA with country } L \\ c_{H}-c_{L}-2 t_{L}^{H} & \text { under the FTA with country } H\end{cases}
$$

Then the welfare-improving condition is given by

$$
c_{H}>c_{L}+\left(t_{L}^{H}-t_{H}^{L}\right)
$$

The tariff rate required, $t_{H}^{L}$, leading to the same total import volume as in the FTA with country $L$, should satisfy (19), i.e.,

$$
t_{L}^{H}=\frac{n_{H}}{n_{L}} \cdot \frac{\frac{1}{s_{L}}-\lambda_{L} P^{\prime}\left(X_{T}\right)}{\frac{1}{s_{H}}-\lambda_{H} P^{\prime}\left(X_{T}\right)} t_{H}^{L},
$$

which allows us to rewrite the welfare-improving condition (22) as follows.

Proposition 6 Suppose that the marginal costs are given by (BP-MC). When the importing country initially forms a FTA with country $L$ with the external tariff $t_{H}^{L}$ to country $H$, then its switch in the FTA partner to country $H$ while keeping the total import constant makes the importing country's welfare better off if there holds

$$
c_{H}>c_{L}+\left\{\frac{n_{H}}{n_{L}} \cdot \frac{\frac{1}{s_{L}}-\lambda_{L} P^{\prime}\left(X_{T}\right)}{\frac{1}{s_{H}}-\lambda_{H} P^{\prime}\left(X_{T}\right)}-1\right\} t_{H}^{L} .
$$

There are a couple of interesting special cases for discussion. First, consider the case discussed by Bhagwati and Panagriya (1996), i.e., $c_{H}>c_{L}$ and $0<s_{L}<s_{H}=+\infty$. Then 
the welfare-improving condition is given by

$$
c_{H}>c_{L}+\left\{\frac{n_{H}}{n_{L}} \cdot \frac{\frac{1}{s_{L}}-\lambda_{L} P^{\prime}\left(X_{T}\right)}{\left(-\lambda_{H} P^{\prime}\left(X_{T}\right)\right)}-1\right\} t_{H}^{L} .
$$

As the braced term on the right hand side is strictly positive for $n_{H} \geq n_{L}$, the importing country finds it more beneficial to form a FTA with the exporting country having the higher export-choke price and more firms, i.e., the country which is less efficient but more competitive in the sense that it has more active firms.

The second is the case in which the two exporting countries are symmetric except the export choke price $c_{i}$, then the welfare-improving condition in the above proposition reduces to $c_{H}>c_{L}$. Thus it is more preferable for the importing country to form a FTA with country $H$ having the higher export-choke price than with country $L$.

Now we can further extend the present approach to welfare comparison between any two tariff policies, $\boldsymbol{t}^{\prime}:=\left(t_{H}^{\prime}, t_{L}^{\prime}\right)$ and $\boldsymbol{t}^{\prime \prime}:=\left(t_{H}^{\prime \prime}, t_{L}^{\prime \prime}\right)$. In view of $(20)$, we may rewrite the welfareimproving condition above and establish

Proposition 7 Suppose that the marginal costs are given by (BP-MC), and consider any two tariff policies $\boldsymbol{t}^{\prime}:=\left(t_{H}^{\prime}, t_{L}^{\prime}\right)$ and $\boldsymbol{t}^{\prime \prime}:=\left(t_{H}^{\prime \prime}, t_{L}^{\prime \prime}\right)$ satisfying

$$
\sum_{k} n_{k} \cdot \frac{t_{k}^{\prime}}{\frac{1}{s_{k}}-\lambda_{k} P^{\prime}\left(X_{T}\right)}=\sum_{k} n_{k} \cdot \frac{t_{k}^{\prime \prime}}{\frac{1}{s_{k}}-\lambda_{k} P^{\prime}\left(X_{T}\right)}>0
$$

where $X_{T}$ is the equilibrium total import volume associated with the tariff policy $\boldsymbol{t}^{\prime}$. When the change in the tariff policies from $\boldsymbol{t}^{\prime}$ to $\boldsymbol{t}^{\prime \prime}$ entails import expansion from country $H$, then the importing country gest better off by such a policy switch if there holds

$$
c_{H}-c_{L}>\left(t_{L}^{\prime}+t_{L}^{\prime \prime}\right)-\left(t_{H}^{\prime}+t_{H}^{\prime \prime}\right)
$$

If the change in the tariff policies entails import expansion from country L, the welfareimproving condition is given by (BT) where the inequality is reversed.

Proposition 6 is a special case of the above proposition where the two tariff policies are those associated with FTA formations. We may also use this proposition to compare the welfares between the uniform tariff policy and the FTA formation. Consider any uniform tariff rate $t^{U}$ as the initial tariff policy. Then Proposition 7 indicates that, given the total import volume under the uniform tariff policy, the FTA formation with country $H$ is better for the importing country than the uniform tariff policy if there holds $c_{H}-c_{L}>t_{L}^{H}$ where $t_{L}^{H}>0$ follows from (TC), which holds when $c_{H}$ is sufficiently greater than $c_{L} .{ }^{15}$

\footnotetext{
${ }^{15}$ Of, this cost difference should be too large, for the importing country finds it optimal to exclude the imports from country $H$ even when it is constrained to employ uniform tariff policies. See footnotes 5 and 12 .
} 
On the hand, what if the importing country forms a FTA with country $L$ instead of employing the uniform tariff policy. Then the welfare-improving condition is given by $c_{H}-$ $C_{L}<-t_{H}^{L}$, where $t_{H}^{L}>0$ follows from (TC). Since this never holds, the importing country gets strictly worse off than under the uniform tariff policy after forming a FTA with country $L$. Of course, the proposition never denies the possibility of the importing country's welfare improvement by adjusting the external tariff and thus the total import volume, though such a possibility is extremely limited.

Corollary 1 Suppose that the marginal costs are given by (BP-MC) in both exporting countries. Then when the importing country switch the trade policy from any uniform tariff $t^{U}(>0)$ to a FTA formation by keeping the total import volume, it always gets worse off by choosing country $L$ as the FTA partner, while it gets better off by choosing country $H$ when there the choke price of country $H$ is greater than that of country $L$ plus the external tariff $t_{L}^{H}$ required under the FTA.

As with the welfare-improving FTA formation with country $H$ mentioned in the above corollary, there are two remarks in order here. First, when the initial uniform tariff policy is the optimal one maximizing the importing country's welfare, the welfare improvement discussed above implies that the FTA formation with country $H$ is further beneficial because the importing country can adjust the external tariff rate.

Second, the switch in the trade policy mentioned in Proposition 7 implies that the postFTA external tariff rate becomes higher than the initial uniform tariff rate. But as pointed above, the importing country can realize further welfare improvement by the external tariff rate, so that it may be better off even with the lower external tariff than under the optimal uniform tariff policy. In fact, this is likely enough to happen if the initial uniform tariff rate is not optimal but sufficiently higher than the optimal level.

\section{Extensions of Analysis and Concluding Remarks}

Our analysis in the preceding sections has elucidated that the importing country, when it forms a FTA, has an incentive to choose the exporting country with the smaller marginal import costs. And when we confine ourselves to either constant or linearly increasing marginal costs, the marginal cost from the country with the lower choke price (i.e., the smaller $c_{i}$ ) becomes

smaller. In this sense, the importing country tends to choose the less efficient exporting country as its FTA partner.

\subsection{Tariff Discrimination with Domestic Production}

There are several possible directions for extending the analysis. The most important is incorporation of domestic production by the importing country. Insofar as we confine ourselves to 
perfect competition, it is immediate to apply our discussion to such a case, for we may replace the gross consumption benefit function with the gross import benefit one. ${ }^{16}$ Extension to imperfect competition is not so hard, either.

For the convenience of description, we hereafter call the importing country the "home country" with super- or sub-scripts $M$. Let us denote by $x_{M}$ the individual output of the domestic firms, by $C_{M}\left(x_{M}\right)$ its total cost function, by $n_{M}$ the number of firms, by $\lambda_{M}$ its conjectural variations and by $X_{M}:=n_{M} x_{M}$ the total domestic output in the home country. Then its welfare is now expressed by

$$
W=U\left(Z_{T}\right)-n_{M} C_{M}\left(\frac{X_{M}}{n_{M}}\right)-\sum_{k=H, L} X_{k} \cdot I M R^{k}\left(X_{k}, Z_{T}\right),
$$

where $Z_{T}:=\sum_{k=H, L, M} X_{k}$ denotes the total output. The equilibrium condition for each industry in each country is still expressed by (9) where $X_{T}$ is now replaced with $Z_{T}$ and we newly introduced $t_{M}$ denoting the specific production tax on the domestic firms. The analysis can be easily compared to the previous one once we devise the quasi-reaction function of the domestic industry which represents its equilibrium total output gainst the total imports $X_{T}$ as follows.

Let $R^{M}\left(Z_{T}, t_{M}\right)$ indicate the quasi-reaction function of the domestic industry, and consider the market equilibrium condition given $X_{T}$, i.e.,

$$
Z_{T}=R^{M}\left(Z_{T}, t_{M}\right)+X_{T}
$$

which defines the total output as a function of the total import given the tax on the domestic firms, i.e., $Z_{T}=\widehat{Z}^{T}\left(X_{T}, t_{M}\right)$. Substitute this for $Z_{T}$ in $R^{M}\left(Z_{T}, t_{M}\right)$ and let $\widehat{R}^{M}\left(X_{T}, t_{D}\right):=$ $R^{M}\left(\widehat{Z}^{T}\left(X_{T}, t_{M}\right), t_{M}\right)$ express its new quasi-reaction function. Then we may rewrite the welfare of the home country as below.

$$
\begin{aligned}
\widehat{W}\left(\boldsymbol{X}, t_{M}\right) & =U\left(X_{T}+\widehat{R}^{M}\left(X_{T},, t_{M}\right)\right)-n_{M} C_{M}\left(\frac{\widehat{R}^{M}\left(X_{T}, t_{M}\right)}{n_{M}}\right) \\
& -\sum_{k=H, L} X_{k} \cdot \widehat{I M R}^{k}\left(X_{k}, X_{T}, t_{M}\right),
\end{aligned}
$$

where $\boldsymbol{X}:=\left(X_{H}, X_{L}\right)$ and $\widehat{I M R}^{i}\left(X_{i}, X_{T}, t_{M}\right):=I M R^{i}\left(X_{i}, X_{T}+\widehat{R}^{M}\left(X_{T}, t_{M}\right)\right)$. The opti-

\footnotetext{
${ }^{16}$ Insofar as the domestic market is perfectly competitive, the consumption benefits minus the domestic production depends only on the domestic price, which also uniquely determines the total import demand. Taking the inverse of the import demand function, we can then express the consumption benefits minus the domestic production costs as a function of the total import volume, which serves as our $U\left(X_{T}\right)$ in the text.
} 
mal tariff discrimination then requires $\frac{\partial \widehat{W}\left(\boldsymbol{X}^{D}, t_{M}\right)}{\partial X_{i}}=0$, which gives rise to

$$
\begin{aligned}
t_{i}^{D} & =x_{i}^{D} C_{i}^{\prime \prime}\left(x_{i}^{D}\right)+X_{i}^{D} \frac{\partial \widehat{I M R}^{i}\left(X_{i}^{D}, X_{T}^{D}, t_{M}\right)}{\partial X_{i}}+\sum_{k=H, L} X_{k}^{D} \frac{\partial \widehat{I M R}^{i}\left(X_{i}^{D}, X_{T}^{D}, t_{M}\right)}{\partial X_{T}} \\
& +\widehat{I M R}^{M}\left(X_{M}^{D}, X_{T}^{D}, t_{M}\right)\left(-\frac{\partial \widehat{R}^{M}\left(X_{T}^{D}, t_{M}\right)}{\partial X_{T}}\right),
\end{aligned}
$$

where $X_{M}^{D}:=\widehat{R}^{M}\left(X_{T}^{D}, t_{M}\right)$ and use was made of (9) for the domestic firms. Compared with the case of no domestic production mentioned in Proposition 4, the last positive common term, showing the effect of the individual monopoly rent earned by the domestic industry, is newly added to the optimal tariff formula. And, given the production tax on the domestic firms, $t_{M}$, the difference in the optimal discriminatory tariffs is still characterized by Proposition 3 .

One possible difference compared with the previous discussion can be found when the marginal cost of each firm is constant and we allow the government of the home country to optimally set the production tax on the domestic firms and maximize the welfare. The government tries to preclude any imports from the country with the greater marginal costs than the domestic firms. This can be shown as follows.

First, when the marginal costs are constant, the optimal discriminatory tariff on the import from country $i$ is given by

$$
t_{i}^{D}=-\frac{\lambda_{i}}{n_{i}} X_{i} P^{\prime}\left(Z_{T}^{D}\right)-P^{\prime \prime}\left(Z_{T}^{D}\right)\left\{1+\frac{\widehat{R}^{M}}{\partial X_{T}}\right\} \sum_{k=H, L} \frac{\lambda_{k}}{n_{k}} X_{k}^{D 2}+\left(P\left(Z_{T}^{D}\right)-c_{M}\right)\left(-\frac{\widehat{R}^{M}}{\partial X_{T}}\right)
$$

where use was made of $I M R^{i}\left(X_{i}, Z_{T}\right)=-\frac{\lambda_{i}}{n_{i}} X_{i} P^{\prime}\left(Z_{T}\right)$.

Second, the optimum condition for choosing the domestic production tax, i.e., $\frac{\partial \widehat{W}}{\partial t_{M}}=0$, yields

$$
P\left(Z_{T}^{D}\right)-c_{M}=-P^{\prime \prime}\left(Z_{T}^{D}\right) \sum_{k=H, L} \frac{\lambda_{k}}{n_{k}} X_{k}^{D 2}<0
$$

which implies that the government actually heavily subsidizes the domestic production.

Put this into the previous tariff formula, and obtain $t_{i}^{D}=\left(P\left(Z_{T}^{D}\right)-c_{i}-t_{i}^{D}\right)+P\left(Z_{T}^{D}\right)-$ $c_{M}$, or equivalently

$$
\frac{t_{i}^{D}}{2}=P\left(Z_{T}^{D}\right)-\frac{c_{i}+c_{M}}{2} .
$$

Thus in view of (9), there holds

$$
-\frac{\lambda_{i}}{n_{i}} X_{i}^{D} P^{\prime}\left(Z_{T}^{D}\right)=P\left(Z_{T}^{D}\right)-c_{i}-t_{i}^{D}=\frac{c_{M}-c_{i}}{2} \leq 0,
$$


which implies $X_{i}^{D}=0$.

Proposition 8 Suppose that the marginal costs of firms are constant in each country. Then when the home country's government sets the optimal tax-cum-subsidies on the domestic industry as well as the tariffs on the imports from abroad, the optimal tariff discrimination precludes the imports from the exporting country with the greater marginal costs than the domestic industry.

\subsection{FTA Formation and Gains from Export Expansion}

The second extension is the model to take account of the gains as the FTA partners. FTA agreements give mutual tariff reduction between the partners, so that each country as the exporter to the partner can also gain the benefits from export expansion. By extending our model in the previous section to the familiar reciprocal dumping model discussed by Brander and Krugman (1983), we can explore this problem. ${ }^{17}$

More specifically, consider the world of three countries, $M, H, L$, where $M$ denotes now simply the third country $M$. Each country has the identical demand function, $n_{i}$ identical firms with conjectural variation $\lambda_{i}$ and constant marginal costs $c_{i}$ where $c_{L}<c_{M}<c_{H}$. We assume that each country's market is segmented. Then our previous analysis is the one just focusing on an individual country's domestic market.

As we have discussed, each country as an importer has an incentive to choose the exporting country with the greater marginal cost, so that countries $H$ and $M$ want to accept each other as the FTA partner but country $H$, though desiring a FTA with country $M$, cannot form any FTA. Even from the viewpoint of an exporter, countries $H$ and $M$ would prefer a FTA between $H$ and $M$. This is because when either forms a FTA with country $L$ with the least marginal costs, it faces the more aggressive competition with the smaller profits than under the FTA with the other country.

\subsection{Directions for Further Research}

We have explored the FTA formation among the countries trading a homogeneous good. Among the limitations of the approach, the greatest one is due to our partial equilibrium approach. A country, trading various types of commodities and services, cannot decide its trade policy on any specific good without taking account of the possible effects on the trade of other goods. Whether the markets are perfectly or imperfectly competitive, it is necessary to incorporate this feature of interdependence in trade, i.e., substitution and complementarity among the traded goods. ${ }^{18}$

\footnotetext{
${ }^{17}$ For example, Yi (1996) and Yi (2000) build a general equilibrium model of reciprocal dumping and discuss the welfare change due to a country's participating in a FTA or a CU by taking account of the gains as the exporter, though the countries are all symmetric.

${ }^{18}$ Hwan and Mai (1991) discusses the problem of tariff discrimination for product differentiaion by using a quadratic utility function. They explore how the cross substitution term in the linear demand affects the tariff
} 
There have already been many studies dealing this issue, but, to my best knowledge, most of them depend on the model specification, often assuming symmetric among the countries, which facilitates computation of equilibria and welfare without shedding lights on what motivates each country's choice of the partner for FTA formation or economic integration in general. There is still much to be done.

\section{References}

Baldwin, R., And A. Venables (1995): "Regional economic integration," in Handbook of International Economics, Vol. III, ed. by G. Grossman, and K. R. Rogoff, chap. Regional economic integration, pp. 1597-644. North Holland.

Bhagwati, J., and A. Panagriya (1996): "The Economics of Preferential Trade Agreements," in Preferential trading areas and multilateralism: strangers, fiends or foes?, ed. by J. Bhagwati, and A. Panagriya, chap. Preferential trading areas and multilateralism: strangers, fiends or foes?, pp. 1-78. AEI Press.

Brander, J. A., and P. R. Krugman (1983): "A 'reciprocal dumping" model of international trade," Journal of International Economics, 15, 313-323.

Brander, J. A., AND B. J. Spencer (1984): "Tariff protection and imperfect competition," in Monopolistic Competition and Inernational Trade, ed. by H. Kierzkowski, chap. Tariff protection and imperfect competition, pp. 194-206. Oxford University Press.

CABral, L. M. B. (1995): "Conjectural variations as a reduced form," Economics Letters, $49,397-402$.

Gatsios, K. (1990): "Preferential tariffs and the "most favored nation" clause: a note," Journal of International Economics, 28, 365-373.

Gaudet, G. O., and S. W. Salant (1991): "Uniquenessof Cournot equilibrium: new results from old methods," Review of Economic Studies, 58, 399-404.

Hahn, F. H. (1962): "The stability of the Cournot oligopoly solution," Review of Economic Studies, 29, 329-331.

Hwan, H., and C. MaI (1991): "Optimum discriminatory tariffs under oligopolistic competition," Canadian Journal of Economics, 24, 693-702.

Kamien, M. I., and N. L. Schwartz (1983): "Conjectural variations," Canadian Journal of Economics, 16, 191-211.

levels and its difference between the two exporting countries. 
Kiyono, K. (1993): "Who will be called partner?: an importing country's incentive to form a free trade are," Economic Studies Quarterly (now renamed Japanese Economic Review), 44, 289-310.

Kolstad, C., and L. Mathiesen (1987): "Necessary and sufficient conditions for uniqueness of a Cournot equilibrium," Review of Economic Studies, 65, 681-690.

McMillan, J., and E. MacCann (1981): "Welfare effects in customs unions," Economic Journal, 91, 697-703.

OkUGUCHI, K. (1976): Expectations and stability in oligopoly models. Springer-Verlag.

PANAgariya, A. (2000): "Preferential trade liberalization: the traditional theory and new developments," Journal of Economic Literature, 38, 287-331.

RAfF, H. (2001): "Review of International Economics," Preferential Trade Liberalization under Cournot Competition, 9, 455-461.

SAGgi, K. (2004): "Tariffs and the most favored nation clase," Journal of International Economics, 63, 341-368.

Viner, J. (1950): The Customs Union Issue. Carnegie Endowment for International Peace.

YI, S. (1996): "Endogenous formation of customs unions under imperfect cmpetition: open regionalism is good," Journal of International Economics, 41, 153-77.

(2000): "Free-trade areas and welfare: an equilibrium analysis," Review of International Economics, 8, 336-347. 